\title{
Glycemic Control and Rate of Sputum Conversion in Diabetic Patients with Pulmonary Tuberculosis
}

\section{Denisse Martínez-Oceguera ${ }^{1,2}$ and Rafael Laniado-Laborín ${ }^{1-3 *}$}

${ }^{1}$ Clínica y Laboratorio de Tuberculosis, Hospital General Tijuana, México

${ }^{2}$ Facultad de Medicina y Psicología, Universidad Autónoma de Baja California

${ }^{3}$ Sistema Nacional de Investigadores, CONACYT

*Corresponding author: Rafael Laniado-Laborín, Emiliano Zapata 1423, Zona Centro, Tijuana, Mexico, Tel: 52 (664) 686-5626; Fax: 52 (664) 686-5626; E-mail: rlaniado@uabc.edu.mx

Received date: Dec 21, 2015; Accepted date: Feb 10, 2016; Published date: Feb 17, 2016

Copyright: (c) 2016 Oceguera DM, et al. This is an open-access article distributed under the terms of the Creative Commons Attribution License, which permits unrestricted use, distribution, and reproduction in any medium, provided the original author and source are credited.

\begin{tabular}{l} 
Abstract \\
Introduction \\
The negative impact of DM and glycemic control on tuberculosis outcomes has been the subject of controversy. \\
Twenty percent of tuberculosis (TB) cases in México are also diabetic; adequate control of glycaemia in Mexican \\
patients due to several socioeconomic factors is rarely accomplished. Our objective was to determine the impact of \\
glycemic control on sputum conversion and to compare the time for sputum smear and culture conversion \\
amongst TB patients with or without diabetes. \\
Setting \\
Referral center for drug-resistant TB and TB complications. Retrospective analysis of cases treated during a five- \\
year period. \\
Results \\
88 patients were referred for treatment; 30 patients $(34.1 \%)$ had DM as a comorbidity. Twenty-seven ( $30.6 \%)$ \\
had TB due to a multidrug resistant (MDR) strain; of the 30 TB-DM patients, 13 had MDR-TB ( $43.3 \%$ ). \\
During follow-up, $27.6 \%$ of TB patients had converted their culture by day 60 vs. $26.6 \%$ of the TB + DM \\
patients (p = 0.58). Culture conversion for TB + DM patients with HbAlc $\geq 6.5 \%$ took $74.7 \pm 32.2$ days vs. $90.0 \pm$ \\
25.3 days in patients with TB + DM and an HbAlc $<6.5 \%$ (p = 0.26). \\
Conclusion \\
Time for smear and culture conversion was not significantly different in patients with TB and patients with TB \\
+ DM, including cases with inadequate glycemic control and those with MDR-TB. \\
\hline
\end{tabular}

Keywords: Tuberculosis; Diabetes; Bacteriological conversion; Glycaemia

\section{Introduction}

DM Mellitus (DM) is a known risk factor for the development of active tuberculosis (TB), and an estimated $15 \%$ of patients with TB in countries with a high TB burden have DM [1].

The negative impact of DM and glycemic control on tuberculosis outcomes has been the subject of controversy. The bacteriological conversion has been reported to be slower in patients with DM in comparison to that of non-diabetic patients in some reports [2-4], and uncontrolled $\mathrm{DM}(\mathrm{HbAlc} \geq 7)$ has been reported as a significant risk factor for positive sputum culture after two months [5]. Other reports, however, do not show DM to be an independent risk factor associated with increased time to sputum conversion [6] or any relation between $\mathrm{DM}$ and sputum conversion rate at the end of the 2nd month $[7,8]$.

The prevalence of DM in México has increased alarmingly in the past two decades and it currently causes $14 \%$ of all deaths in the country. DM is one of the main comorbidities associated to TB in Mexico; 20\% of TB cases in México are also diabetic [9]. Adequate control of glycaemia in Mexican patients is very rare; in a national survey, only $6.6 \%$ of those diagnosed with DM had HbAlc $<7 \%$. $[3,10]$.

Our objective was to determine the impact of glycemic control on sputum conversion and to compare the time for sputum smear and culture conversion amongst TB patients with or without diabetes. 
Page 2 of 3

\section{Material and Methods}

The Tuberculosis Clinic at the Tijuana General Hospital, Mexico is a regional referral center for patients with drug-resistant TB and TB in special situations (adverse reactions to drugs, pregnancy, etc.) located in Tijuana, Mexico. Tijuana is the city with the highest TB rate (50 per $100,000 \mathrm{~h}$ ) in Mexico.

A review of the clinical charts for the period June 2009-December 2014 was carried out to extract demographic, clinical and microbiologic data for patients treated during that period. All cases had baseline culture and drug susceptibility tests (DST) for first-line drugs (MGIT 960', Beckton Dickinson, New Jersey) as well as monthly Lowenstein-Jensen solid cultures during clinical follow-up. Second line DST was carried out (MGIT and pyrosequence) for rifampin-resistant and MDR-TB cases. Monthly central glycaemia and glycosylated hemoglobin (HbAlc) every 3 months were obtained for patients with TB+DM. Patients with DM were treated with metformin and dietary restriction. All our patients are under strict DOT by a health promoter.

The study protocol was reviewed and authorized by the Ethics Committee of the institution. Data was analyzed for descriptive and inferential statistics. Differences in categorical variables were analyzed utilizing the $\mathrm{x}^{2}$ test. The independent samples t-test was used for the analysis of culture conversion time. The analysis was performed with the commercial statistical package SPSS version 21 (IBM Corporation, Armonk, New York).

\section{Results}

During this period $71(80.7 \%)$ patients with drug-resistant TB (DRTB) and 17 patients (19.3\%) with adverse reactions to antituberculosis drugs (ARTD) were referred for treatment; 30 patients $(34.1 \%)$ had $\mathrm{DM}$ as a comorbidity and $58(65.9 \%)$ did not. Seventy-nine $(89.7 \%)$ were discharged as cured and 1 patient (1.1\%) failed (non-diabetic). Seven patients $(7.9 \%)$ were lost to follow-up and one patient $(1.1 \%)$ was transferred to another state; these 8 patients had converted their culture before they were lost to follow-up.

Of the DR-TB cases, 23 (32.4\%) harbored a monoresistant strain (8 were also diabetic), 21 (29.5\%) had a polyresistant strain (7 were diabetic) and 27 (38.0\%) had a multidrug-resistant (MDR) strain; 13 of this later group were also diabetic. Of the 30 TB-DM patients, 13 had MDR-TB (43.3\%).

Twenty of the 54 males in the sample were diabetic (37.0\%) vs. 8 of 34 females $(23.5 \%, \mathrm{p}=0.07)$. Table 1 compares demographic and clinical data of TB patients with and without DM. Patients with TB + DM were significantly older than TB patients without DM.

\begin{tabular}{|l|l|l|l|}
\hline Variable & TB+DM & TB & $\mathbf{p}$ \\
\hline Age (years) & $50.6 \pm 12.4$ & $33.2 \pm 12.8$ & $<0.0001$ \\
\hline Body Mass Index (BMI) & $23.3 \pm 5.3$ & $20.17 \pm 3.4$ & 0.026 \\
\hline Baseline central glycaemia & $173.0 \pm 73.5$ & $92.9 \pm 9.7$ & $<0.0001$ \\
\hline $\begin{array}{l}\text { Central glycaemia at time of } \\
\text { conversion }\end{array}$ & $168.5 \pm 89.5$ & $92.1 \pm 13.2$ & $<0.0001$ \\
\hline $\begin{array}{l}\text { Smoking (pack years) } \\
\text { Treatment regimens for TB in } \\
\text { the past }\end{array}$ & $1.81 \pm 3.7$ & $1.70 \pm 8.9$ & 0.62 \\
\hline
\end{tabular}

$1.87 \pm 3.7$

$2.24 \pm 4.4$

0.69

Table 1: Demographic and clinical baseline variables.

Table 2 utilizing the of days needed for smear and culture conversion; $27.6 \%$ of TB patients had converted their culture by day 60 vs. $26.6 \%$ of the $\mathrm{TB}+\mathrm{DM}$ patients $(\mathrm{p}=0.58)$. Patients with $\mathrm{TB}+\mathrm{DM}$ that had an average $\mathrm{HbAlc} \geq 6.5 \%$ converted their sputum smears in $68.9 \pm 52.3$ days vs. $110.7 \pm 47.2$ days in patients with $\mathrm{TB}+\mathrm{DM}$ and a HbAlc $<6.5 \%(\mathrm{p}=0.11)$. Culture conversion for TB + DM patients with $\mathrm{HbA1c} \geq 6.5 \%$ took $74.7 \pm 32.2$ days vs. $90.0 \pm 25.3$ days in patients with $\mathrm{TB}+\mathrm{DM}$ and $\mathrm{HbA1c}<6.5 \%(\mathrm{p}=0.26)$. There were no significant differences amongst the groups in the extent of pulmonary lesions as measured by the number of affected quadrants ( $1.53 \pm 0.7$ for $\mathrm{TB}+\mathrm{DM}$ vs. $1.53 \pm 0.7$ for $\mathrm{TB} ; \mathrm{p}=0.82$ ), the number of lung cavities $(1.27 \pm 0.9$ vs. $1.33 \pm 1.3 ; \mathrm{p}=0.26)$ and the presence or absence of mediastinal retraction $(16.1 \%$ vs. $27.6 \% ; \mathrm{p}=0.17)$ as shown in the chest radiograph.

\begin{tabular}{|l|l|l|l|}
\hline Variable & TB + DM & TB & $\mathbf{p}$ \\
\hline $\begin{array}{l}\text { Affected quadrants in the } \\
\text { chest }\end{array}$ & $1.73 \pm 0.87$ & $1.53 \pm 0.75$ & 0.82 \\
\hline Number of lung cavities & $1.27 \pm 0.98$ & $1.33 \pm 1.36$ & 0.26 \\
\hline Mediastinal retraction & $16.1 \%$ & $27.6 \%$ & 0.17 \\
\hline $\begin{array}{l}\text { Smears: time to conversion } \\
\text { (days) }\end{array}$ & $77.8 \pm 48.1$ & $71.6 \pm 51.5$ & 0.59 \\
\hline $\begin{array}{l}\text { Culture: time to conversion } \\
\text { (days) }\end{array}$ & $80.3 \pm 28.1$ & $88.6 \pm 42.7$ & 0.33 \\
\hline
\end{tabular}

Table 2: Disease severity and time to bacteriologic conversion.

There were no significant differences between patients with $\mathrm{TB}+$ DM and patients with TB in time to conversion when patients with a monoresistant strain are classified according to resistance to a specific drug. Patients with MDR-TB and DM converted their culture in $93.5 \pm$ 57.5 days vs. $75.9 \pm$ days for patients with MDR-TB without DM ( $\mathrm{p}=$ 0.07). Patients with MDR-TB $+\mathrm{DM}$ and adequate glycemic control $(\mathrm{HbA} 1 \mathrm{c}<6.5 \%)$ converted their culture in $90.5 \pm 32.7$ days vs. $65 \pm$ 44.1 days for patients with MDR-TB + DM and inadequate glycemic control $(\mathrm{p}=0.36)$.

\section{Discussion}

$\mathrm{DM}$ is a well-known predisposing factor for the development of active $\mathrm{TB}$ and is a highly prevalent co-morbidity in patients with DR$\mathrm{TB}$, with rates up to $20 \%$ in patients with MDR-TB [1].

The vast majority of patients with $\mathrm{TB}+\mathrm{DM}$ in Mexico are poor and are not able to follow the dietary recommendations that complement their pharmacologic treatment, resulting in inadequate control of their metabolic disease. Various socioeconomic conditions in Mexico may have favored changes in diet, including slow economic growth, rising social inequality, declining agriculture production, decreased wages in relation to the increasing prices of healthy food and the low cost of processed foods and sugary refreshments [11]. Glycemic control in our patients was, in general, poor, but it was not correlated to delayed culture conversion, regardless of the presence or not of drug resistance. 
The effect of glycemic control on sputum conversion in patients with $\mathrm{TB}+\mathrm{DM}$ as mentioned has been a polemic issue. For example Chang et al. reported a delayed clearance of mycobacteria in patients with TB + DM when compared with TB patients without DM $(2.5 \pm$ 3.0 months vs. $1.6 \pm 1.4$ months, $\mathrm{p}<0.01$ ) [2].

In contradiction, several reports have not found differences in culture conversion time in TB patients with and without diabetes. Magee et al. found no difference in culture conversion between patients in Georgia with MDR-TB + DM and patients with MDR-TB (adjusted hazard ratio [aHR] 0.95, 95\% CI 0.71-1.28 [12]. Similar results have been reported in studies conducted in Morocco [13], the United States [14], India [15], Fiji [16] and in a multinational study that included MDR-TB patients from Peru, Estonia, Russia and the Philippines [17].

Although it seems that deficient glycemic control does not correlate negatively with time for culture conversion, diabetes clearly has a negative impact on TB treatment outcomes, with higher failure, relapse, and mortality rates [18].

\section{Conclusion}

In our clinical experience, even patients with less than adequate glycemic control will convert their cultures when an effective drug regimen is strictly supervised. Although we try to achieve optimal metabolic control in all patients with $\mathrm{TB}+\mathrm{DM}$, the socioeconomic barriers already described will hinder this effort. The social drivers of disease in Mexico must be addressed; biomedical interventions by themselves will not be able to control the epidemic.

\section{References}

1. Magee MJ, Bloss E, Shin SS, Contreras C, Arbanil-Huamane HJ, et al. (2013) Clinical characteristics, drug resistance, and treatment outcomes among tuberculosis patients with DM in Peru. International J Infect Dis 17: e404-e412.

2. Chang JT, Dou HY, Yen CL, Wu YH, Huang RM, et al (2011) Effect of Type 2 DM Mellitus on the Clinical Severity and Treatment Outcome in Patients with Pulmonary Tuberculosis: A Potential Role in the Emergence of Multidrug-resistance. J Formos Med Assoc 110: 373-381.

3. Jiménez-Corona ME, Cruz-Hervert LP, García-García L, Ferreyra-Reyes L, Delgado-Sánchez G, et al (2013) Association of DM and tuberculosis: impact on treatment and post-treatment outcomes. Thorax 68: 214-220.

4. Heysell SK, Moore JL, Keller SJ, Houpt ER (2010) Therapeutic drug monitoring for slow response to tuberculosis treatment in a state control program, Virginia, USA. Emerg Infect Dis 16: 1546-1553.
5. Park SW, Shin JW, Kim JY, Park IW, Choi BW, et al. (2012) The effect of diabetic control status on the clinical features of pulmonary tuberculosis. Eur J Clin Microbiol Infect Dis 31: 1305-1310.

6. Singla R, Khan N, Al-Sharif N, Ai-Sayegh MO, Shaikh MA, et al. (2006) Influence of DM on manifestations and treatment outcome of pulmonary TB patients. Int J Tuberc Lung Dis 10: 74-79.

7. Dooley KE, Chaisson RE (2009) Tuberculosis and DM mellitus: convergence of two epidemics. Lancet Infect Dis 9: 737-746.

8. Dooley KE, Tang T, Golub JE, Dorman SE, Cronin W, et al. (2009) Impact of DM mellitus on treatment outcomes of patients with active tuberculosis. Am J Trop Med Hyg 80: 634-639.

9. Pérez-Navarro LM, Fuentes-Domínguez F, Morales-Romero J, ZentenoCuevas R (2011) Factores asociados a tuberculosis pulmonar en pacientes con diabetes mellitus de Veracruz, México. Gaceta Médica de México 147: 219-225.

10. Barquera S, Campos-Nonato I, Aguilar-Salinas C, Lopez-Ridaura R, Arredondo A, et al. (2013) DM in Mexico: cost and management of DM and its complications and challenges for health policy. Globalization and Health 9: 3.

11. Moreno-Altamirano L, Silberman M, Hernández-Montoya D, Capraro S, Soto-Estrada G, et al. (2015) DM tipo 2 y patrones de alimentación de 1961 a 2009: algunos de sus determinantes sociales en México. Gac Med Mex 151: 354-368.

12. Magee MJ, Kempker RR, Kipiani M, Tukvadze N, Howards PP, et al. (2014) DM Mellitus, Smoking Status, and Rate of Sputum Culture Conversion in Patients with Multidrug-Resistant Tuberculosis: A Cohort Study from the Country of Georgia. PLoS ONE 9: e94890.

13. Bouti K, Aharmim M, Marc K, Soualhi M, Zahraoui R, et al. (2013) Factors Influencing Sputum Conversion among Smear-Positive Pulmonary Tuberculosis Patients in Morocco. ISRN Pulmonology.

14. Dooley KE, Tang T, Golub JE, Dorman SE, Cronin W, et al. (2009) Impact of Diabetes Mellitus on Treatment Outcomes of Patients with Active Tuberculosis. Am J Trop Med Hyg 80: 634-639.

15. Rekha VVB, Balasubramanian R, Swaminathan S, Ramachandran R, Rahman F, et al. (2007) Sputum conversion at the end of intensive phase of Category-1 regimen in the treatment of pulmonary tuberculosis patients with diabetes mellitus or HIV infection: An analysis of risk factors. Indian J Med Res 126: 452-458.

16. Prasad P, Gounder S, Varman S, Viney K (2014) Sputum smear conversion and treatment outcomes for tuberculosis patients with and without diabetes in Fiji. PHA 4: 159-163.

17. Kurbatova EV, Gammino VM, Bayona J, Becerra MC, Danilovitz M, et al. (2012) Predictors of sputum culture conversion among patients treated for multidrug-resistant tuberculosis. Int J Tuberc Lung Dis 16: 1335-1343.

18. Skowroński M, Zozulińska ZD, Barinow WA (2014) Tuberculosis and diabetes mellitus - an underappreciated association. Arch Med Sci. 10: 1019-1027. 